\title{
One Novel two-step Bio-Oxidation Pretreatment of Arsenic- Containing Gold-Bearing Concentrate
}

\author{
Ye Zheng ${ }^{1,2}$, Dezhou Wei ${ }^{1, *}$, Wengang Liu $^{1, *}$, Hao Duan ${ }^{1}$, Shijie Zhou ${ }^{l}$ \\ ${ }^{1}$ School of Resources and Civil Engineering, Northeastern University, Shenyang 110819, Liaoning, \\ China \\ ${ }^{2}$ Changchun Gold Research Institute, Changchun, 130012, China \\ *E-mail: dzwei@ mail.neu.edu.cn (Dezhou Wei); liuwengang@ mail.neu.edu.cn (Wengang Liu)
}

doi: $10.20964 / 2018.06 .28$

Received: 23 January 2018 / Accepted: 8 March 2018 / Published: 10 May 2018

\begin{abstract}
A novel process was developed to markedly increase gold cyanidation performance from an arseniccontaining gold-bearing concentrate. Before cyanidation, a two-step bio-oxidation pretreatment was employed to decrease the arsenic content in the residue and obtain a high cyanidation efficiency for gold. Bio-oxidation results indicated that most of the arsenic was rapidly removed from the mineral into the solution in the first bio-oxidation step, and a high redox potential benefited the bio-oxidation process. With an increase in the redox potential of the solution, the As(III) concentration in the solution was decreased. After the first step of the bio-oxidation process, only $4.38 \%$ of the arsenic remained in the residue when the slurry density was 7\%. After the second step of the bio-oxidation process, the arsenic content in the residue was decreased to $1.81 \%$ when the slurry density for the second step of the bio-oxidation process was $14 \%$. Cyanidation tests indicate that the leaching rate of gold could reach $95.66 \%$ after sequential two-step bio-oxidation; this leaching rate was much higher than that of the direct cyanidation and one-step bio-oxidation pretreatment.
\end{abstract}

Keywords: Redox potential; Bio-oxidation; High arsenic gold concentrate; Cyanidation

\section{$\underline{\text { FULL TEXT }}$}

(C) 2018 The Authors. Published by ESG (www.electrochemsci.org). This article is an open access article distributed under the terms and conditions of the Creative Commons Attribution license (http://creativecommons.org/licenses/by/4.0/). 